\title{
A New Approach to Synthesis of Free-Standing ZnO/MWCNT Nanocomposites by Vacuum Infiltration
}

\author{
M. AlaF*, D. Gultekin And H. Akbulut \\ Sakarya University, Metallurgical and Materials Engineering, Esentepe Campus 54187, Sakarya, Turkey

\begin{abstract}
In this study, free-standing zincoxide/multiwalled carbon nanotube nanocomposite was synthesized by a multiwalled carbon nanotubes. Zinc acetate dihydrate $(\mathrm{ZnAc})\left(\mathrm{Zn}\left(\mathrm{CH}_{3} \mathrm{COO}\right)_{2} \cdot 2 \mathrm{H}_{2} \mathrm{O}\right)$ was used as zinc source and dia. The solution was vacuum filtered through buckypaper and annealed at $350{ }^{\circ} \mathrm{C}$ in air. It was found that the zinc oxide grows around the multiwalled carbon nanotubes to form a uniform composite. Morphology of zine oxide/multiwalled carbon nanotube was also studied in detail. Nanocomposite was characterized by X-ray diffraction, scanning electron microscopy, and Raman spectroscopy.
\end{abstract} \\ tistep technique. Buckypapers having controlled porosity were prepared by vacuum filtration from oxidized mul- \\ ethanol used as solvent. An appropriate amount of monoethanolamine was added to sol to change acid-base me-
}

DOI: $10.12693 /$ APhysPolA.125.426

PACS: 81.05.uj, 61.48.De, 78.30.Fs

\section{Introduction}

Paper-like carbon nanotube (CNT) films, also called buckypaper, are self-supporting networks of entangled CNT assemblies arranged in a random fashion and held together by van der Waals interactions at the tube-tube junctions [1]. CNT-based sheets and their composites have become a hot topic in CNT research and can be used as catalysts, sensors, semiconductor devices, and new reinforced nanomaterials [2].

The hybrid structures of CNTs are emerging as an important class of nanostructured materials for fabricating future nanoelectronic devices. Among these hybrid structures, an interesting class of CNT derivatives results from depositing semiconducting nanoparticles/nanoclusters, on the CNT surface. The semiconducting nanoparticles including $\mathrm{ZnO}, \mathrm{TiO}_{2}, \mathrm{SnO}_{2}, \mathrm{CdS}, \mathrm{CdTe}$, CdSe, etc. exhibit size dependent optical, magnetic and electrical properties and their applications span a broad range [3]. Among these semiconducting materials, zinc oxide $(\mathrm{ZnO})$ is an important material and has received considerable attention due to its applications in electrical, optical, mechanical and scientific research as well as industry. $\mathrm{ZnO}$ is a wide band gap $(3.37 \mathrm{eV})$ semiconductor and has a large binding energy $(60 \mathrm{meV})$, low resistivity and high transparency in the visible range and high light trapping characteristics [4].

Recently, the fabrications of $\mathrm{ZnO} /$ multi-walled carbon nanotube (MWCNT) nanocomposites have gained interest among the materials scientists because of its superior optoelectronic properties [5], photocatalytic properties [6] and their antibacterial activities [7]. Additionally, $\mathrm{ZnO} / \mathrm{MWCNT}$ nanocomposites have potential applications ranging from electrochemical sensors [8], biosensors [9] and supercapacitors [10] to solar cells [11].

In this work, we proposed a new approach to synthesis of free-standing $\mathrm{ZnO} / \mathrm{MWCNT}$ nanocomposite. Zn-based solution synthesized by dissolving zinc acetate $\left(\mathrm{Zn}\left(\mathrm{CH}_{3} \mathrm{COO}\right)_{2} \cdot 2 \mathrm{H}_{2} \mathrm{O}\right)$ in ethanol $\left(\mathrm{C}_{2} \mathrm{H}_{5} \mathrm{OH}\right)$ was infil- trated through MWCNT buckypaper having controlling porosity. Vacuum was under control to growing $\mathrm{ZnO}$ nanoparticles into pores of buckypaper. Synthesized nanocomposite was subject to microscopic and spectroscopic analyses for confirming their microstructure and chemical properties.

\section{Experimental details}

In our work, $\mathrm{ZnO} / \mathrm{MWCNT}$ nanocomposite was produced with a new approach consisting of several steps. Figure 1 represents the process flow chart used for synthesis of nanocomposite. First step is the preparation of the $\mathrm{Zn}$-based solution by dissolving zinc acetate $\left(\mathrm{Zn}\left(\mathrm{CH}_{3} \mathrm{COO}\right)_{2} \cdot 2 \mathrm{H}_{2} \mathrm{O}\right)$ in ethanol $\left(\mathrm{C}_{2} \mathrm{H}_{5} \mathrm{OH}\right)$ with $0.3 \mathrm{M}$ ratio. Certain amount of monoethanolamine (MEA) was added to solutions to change acid-base media and all chemicals were stirred for $1 \mathrm{~h}$ to form a clear, stable and homogeneous sol at $60^{\circ} \mathrm{C}$.

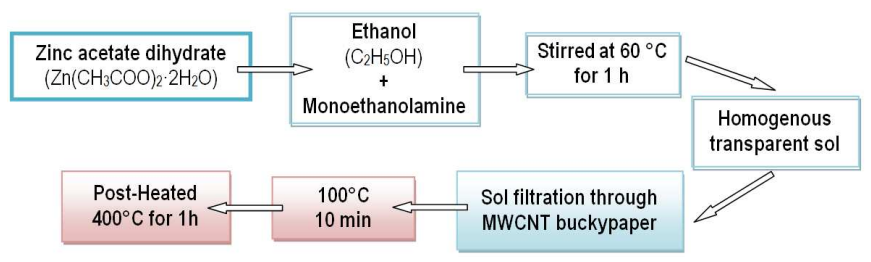

Fig. 1. Process flow chart used for synthesis of nanocomposite.

Second step is production of free-standing MWCNT buckypaper. MWCNTs over $1.0 \mu \mathrm{m}$ in length with the outer diameter of $50 \mathrm{~nm}$ were purchased from Arry Nano (Germany). Since the mechanical properties of buckypapers are primarily determined by the tube-tube interactions, chemical oxidation of the MWCNTs sidewalls and tips could be utilized to increase the modulus and 
strength of the MWCNT buckypapers. Chemical oxidation of MWCNTs was carried out with a mixture of $\mathrm{H}_{2} \mathrm{SO}_{4}$ and $\mathrm{HNO}_{3}$ acids in ratio $3: 1$ for $3 \mathrm{~h}$ after annealing and treating in $\mathrm{HCl}$ acid for impurity removing. The MWCNTs were first dispersed into water by the aid of SDS surfactant and sonicated for $1 \mathrm{~h}$ to form a well dispersed suspension which subsequently was vacuum filtered through PVDF membrane filters of $220 \mathrm{~nm}$ pore size to form buckypapers.

Then the ZnAc solution was infiltrated through MWCNT buckypaper having controlled porosity. Vacuum pressure was kept under control during production. Figure 2 shows the method of preparing $\mathrm{ZnO} / \mathrm{MWCNT}$ nanocomposite. Then, the $\mathrm{ZnO} / \mathrm{MWCNT}$ nanocomposite was dried at $100{ }^{\circ} \mathrm{C}$ for $10 \mathrm{~min}$ and peeled-off from the filtration membrane. The free-standing $\mathrm{ZnO} / \mathrm{MWCNT}$ nanocomposite was post-heated at $400^{\circ} \mathrm{C}$ for $1 \mathrm{~h}$.

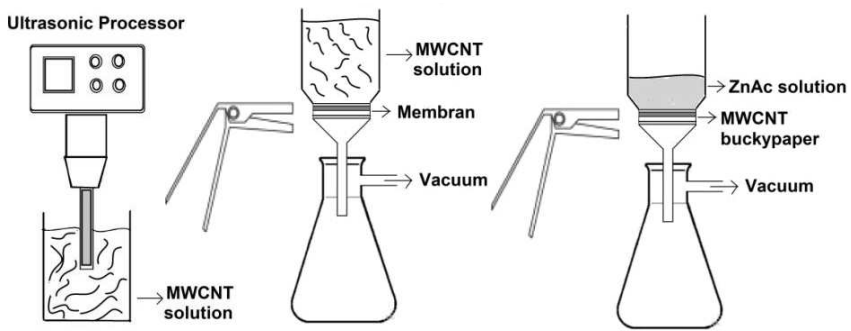

Fig. 2. Schematic representations of method for preparing $\mathrm{ZnO} / \mathrm{MWCNT}$ nanocomposite.

An X-ray diffractometer (XRD-Rigaku D/MAX 2000) with $\mathrm{Cu} K_{\alpha}$ radiation has been used to determine the grain size, crystal structure of resultant nanocomposites. The morphology of the free-standing $\mathrm{ZnO} / \mathrm{MWCNT}$ nanocomposite was investigated by scanning electron microscopy (SEM, JEOL 6060LV). Laser Raman spectra were investigated using a Kaiser Raman RXN Systems from 200 to $2800 \mathrm{~cm}^{-1}$ at room temperature. The $50 \mathrm{~mW}$ $785 \mathrm{~nm}$ near-infrared (NIR) laser was used as the excitation source.

\section{Results}

After calcinations at $400^{\circ} \mathrm{C}, \mathrm{ZnO} / \mathrm{MWCNT}$ nanocomposite was characterized by recording their XRD patterns as shown in Fig. 3. Based on the curve, nanocomposite shows typical peaks of carbon at $2 \theta=26.05^{\circ}$ and $42.45^{\circ}$, assigned to (002) and (100) planes, respectively. The (100), (002), (101), (110), and (112) planes of $\mathrm{ZnO}$ which could respectively be observed at $2 \theta=31.75^{\circ}, 34.35^{\circ}$, $36.20^{\circ}, 56.70^{\circ}$, and $68^{\circ}$ correspond well to the previously reported values [12]. The peak positions in nanocomposite agree well with the reflections of $\mathrm{ZnO}$ and $\mathrm{C}$ with all peaks corresponding well to standard crystallographic data (ZnO:JCPDS Card No. 01-070-2551 C:JCPDS Card No. 00-026-1080). The grain size of the $\mathrm{ZnO}$ was calculated by using Scherrer's formula and the crystallite size is $13.8 \mathrm{~nm}$.

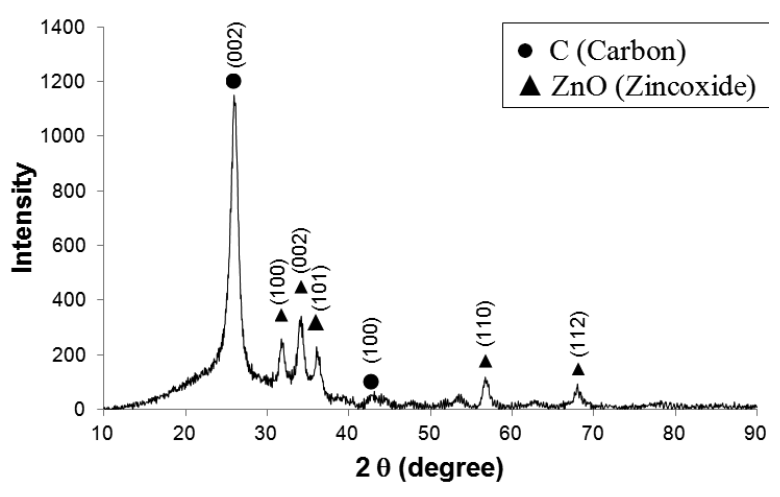

Fig. 3. XRD pattern of $\mathrm{ZnO} / \mathrm{MWCNT}$ nanocomposite.

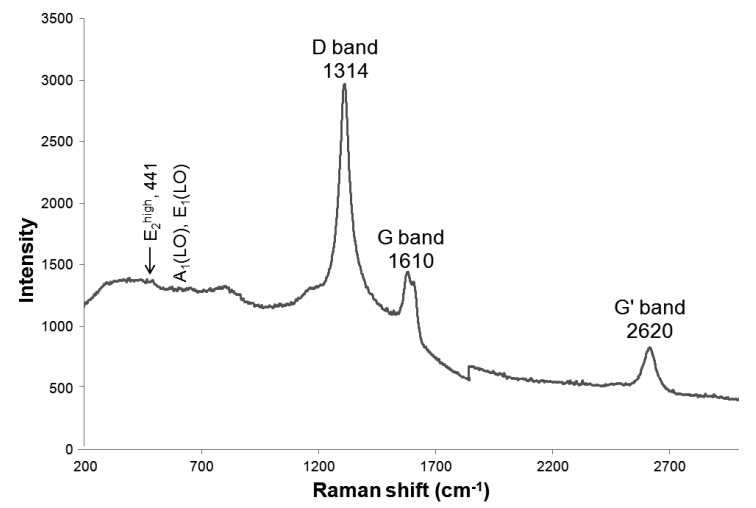

Fig. 4. Raman spectra of $\mathrm{ZnO} / \mathrm{MWCNT}$ nanocomposite.

Figure 4 illustrates the Raman spectra of the $\mathrm{ZnO} /$ MWCNT nanocomposite. The peaks at 1314, 1610, and $2620 \mathrm{~cm}^{-1}$ correspond to the $D$-band (disordered band), $G$-band (graphene band) and $G^{\prime}$-band, respectively. $G$ band originates from graphitic structures $\left(s p^{2}\right)$ [1]. Further Raman signals at $441 \mathrm{~cm}^{-1}\left(E_{2}^{\text {high }}\right), 575 \mathrm{~cm}^{-1}$ $\left(A_{1}(\mathrm{LO})\right)$, and $585 \mathrm{~cm}^{-1}\left(E_{1}(\mathrm{LO})\right)$ are observed for $\mathrm{ZnO}$.

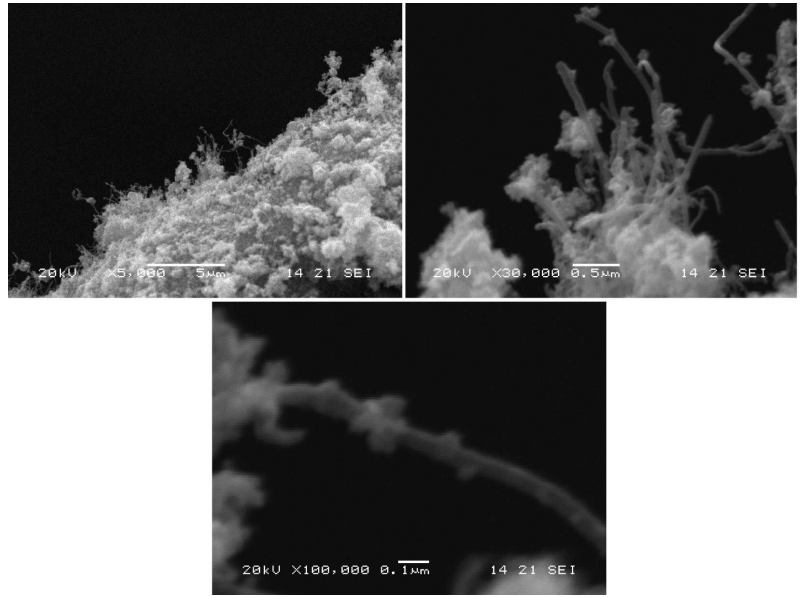

Fig. 5. SEM images of $\mathrm{ZnO} / \mathrm{MWCNT}$ nanocomposite. 
Figure 5 presents scanning electron microscope (SEM) images of $\mathrm{ZnO} / \mathrm{MWCNT}$ nanocomposite at different magnifications. $\mathrm{ZnO}$ nanoparticles are grown in the pores and on the surface of MWCNT paper as shown in Fig. 5a. As can be seen from the higher magnification images (Fig. 5b,c), the MWCNT surface is covered with nanoparticles and also they agglomerate on the tubes.

\section{Conclusions}

In this work the free-standing $\mathrm{ZnO} / \mathrm{MWCNT}$ nanocomposite was successfully synthesized with a new approach. The nanocomposite exhibited the uniform coating layer of $\mathrm{ZnO}$ with grain size of $13.8 \mathrm{~nm}$ in the pores and on the surface of MWCNT paper. XRD analysis confirmed that the nanocomposite consisted of $\mathrm{C}$ and $\mathrm{ZnO}$. The Raman spectrum showed $D$-band, $G$-band and $G^{\prime}$-band of the MWCNT and peaks of $\mathrm{ZnO}$. SEM images verified that $\mathrm{ZnO}$ nanoparticles were homogeneously grown on the tube surfaces and the pores of MWCNT paper. The final product can be used in many applications such as Li-ion batteries, supercapacitor, and solar cells.

\section{Acknowledgments}

The authors would like to acknowledge the financial support of Scientific and Technical Research Council of Turkey (TÜBİTAK) under the contract number 109M464 and Sakarya University, Coordination of Scientific Research Project (BAPK) under the contract number 2009$-50-02-023$.

\section{References}

[1] U. Tocoglu, M. Alaf, O. Cevher, M.O. Guler, H. Akbulut, J. Nanosci. Nanotechnol. 12, 9169 (2012).

[2] J. Klanwan, N. Akrapattangkul, V. Pavarajarn, T. Seto, Y. Otani, T. Charinpanitkul, Mater. Lett. 64, 80 (2010).

[3] I. Sameera, R. Bhatia, V. Prasad, Physica B 405, 1709 (2010)

[4] D. Gultekin, M. Alaf, M.O. Guler, H. Akbulut, J. Nanosci. Nanotechnol. 12, 9175 (2012).

[5] X. Yana, B. Tay, P. Miele, Carbon 46, 753 (2008).

[6] K. Dai, G. Dawson, S. Yang, Z. Chen, L. Lu, Chem. Eng. J. 191, 571 (2012).

[7] M. Sui, L. Zhang, L. Sheng, S. Huang, L. She, Sci. Total Environ. 452-453, 148 (2013).

[8] C. Zhang, G. Wang, M. Liu, Y. Feng, Z. Zhang, B. Fan, Electrochim. Acta 55, 2835 (2010).

[9] V.K. Gupta, P. Norouzi, H. Ganjali, F. Faridbod, M.R. Ganjali, Electrochim. Acta 100, 29 (2013).

[10] Y. Zhang, X. Sun, L. Pan, H. Li, Z. Sun, C. Sun, B.K. Tay, Solid State Ionics 180, 1525 (2009).

[11] J. Du, F. Bittner, D.S. Hecht, C. Ladous, J. Ellinger, T. Oekermann, M. Wark, Thin Solid Films 531, 391 (2013).

[12] D. Gultekin, M. Alaf, H. Akbulut, Acta Phys. Pol. A 123, 274 (2013). 